Boise State University

ScholarWorks

$11-2008$

\title{
Locating Oil Spills Under Sea Ice Using Ground-Penetrating Radar
}

John H. Bradford

Boise State University

Lee M. Liberty

Boise State University

David F. Dickens

DF Dickens Associates 


\section{Locating oil spills under sea ice using ground-penetrating radar}

John H. Bradford and LeE M. Liberty, Boise State University, USA

David F. DICKINS, DF Dickins Associates, LaJolla, California, USA
$\mathrm{T}_{\mathrm{e}}^{\mathrm{h}}$ he accelerating level of interest in arctic oil and gas exploration was demonstrated in the overwhelming response to recent lease sales in the Alaskan OCS region. As development increases, the potential for accidental oil spills in the arctic marine environment increases. The need for reliable systems to detect oil trapped in a range of ice conditions remains at the forefront of continued efforts to improve response to ocean spills.

Crude oil released from a subsea blowout or a marine pipeline rupture will rise through the water column to the surface. If an ice sheet is present, the oil will become trapped at the base of the ice and form an oil layer between the ice and water. The areal distribution of oil is limited by natural variations under ice that provide natural "reservoirs" to effectively contain spilled oil. If we consider first-year ice, oil spilled under early season thin ice will spread over a larger area and be contained in relatively thin pools up to a few centimeters thick. Under thick, late-winter ice, the maximum oil thickness in the deepest pools could reach over $30 \mathrm{~cm}$. Spills under ice during the active solid ice growth period (November-April) will become encapsulated by new ice growth beneath the oil layer.

A concerted Canadian research effort in the 1980s, sponsored by industry and government, analyzed and tested a variety of technologies (including radar, electromagnetic, and acoustic techniques) to detect oil in or under solid ice. Results suggested potential for radar methods, but there was no further development at that time.

Since 2004, we have conducted numerical, laboratory, and field experiments to test the ability of ground-penetrating radar (GPR) to locate oil within or beneath sea ice. Here we begin with a discussion of the physical characteristics of sea ice followed by an introduction to basic GPR concepts as related to oil detection in the sea-ice environment. We then overview our work to date, which includes developing algorithms for realistic modeling of GPR signal propagation through sea ice and controlled spills in the laboratory and natural sea-ice environment.

\section{Formation and properties of sea ice}

Brine inclusion within a growing sea-ice sheet and the subsequent behavior of these brine pockets through the winter has a significant impact on radar attenuation. In addition, the condition of the brine channels at different stages in the ice's growth and melt cycles affect the characteristics of the oil layer, determining for example whether the oil resides as a discrete trapped layer or as a diffuse boundary with vertical migration through all or part of the ice sheet.

Brine is entrapped within an ice sheet during the freezing process in the form of fine pockets of fluid between platelets of pure ice. The amount of salt trapped in the ice is principally dependent on the rate of freezing. As the ice thickens, the growth rate decreases, and brine is expelled more efficiently. At any given temperature, the fluid within the brine channels is always at a salt concentration so that it is in equilibrium with the surrounding pure ice crystals. The dominant salt in seawater $\left(\mathrm{NaCl} . \mathrm{H}_{2} \mathrm{O}\right)$ precipitates out at $-22.9^{\circ} \mathrm{C}$. This means that for brine pockets to exist in a primarily crystalline (nonfluid) state, the ice temperature needs to be below this value. In most areas outside the High Arctic, air temperatures are such that only the upper ice layer will experience temperatures below this threshold for any length of time. Consequently, most entrapped brine will exist in a concentrated fluid state. The gross brine volume $\left(\mathrm{V}_{\mathrm{b}}\right)$ within any sea-ice sheet increases with salinity and temperature. Higher $V_{b}$ leads to increased electric conductivity and therefore inhibits GPR signal penetration.

In a cold sea-ice sheet with a close-to-linear temperature profile connecting the cold surface $\left(<<0^{\circ} \mathrm{C}\right)$ and relatively warm ice/water interface $\left(-1.9^{\circ} \mathrm{C}\right)$, the brine exists in discontinuous pockets. The energy balance favors continual melting of the ice at the warmer end of a brine pocket and refreezing at the colder end. As a result, the pockets tend to migrate towards the higher temperatures at greater depth, becoming larger and longer as they pass into progressively warmer surrounding ice. Eventually, the pockets coalesce to form major continuous channels with diameters in the order of $0.1-10$ $\mathrm{mm}$. In the spring, the ice normally experiences a reversal in temperature gradient with both the upper and lower ice surfaces being warmer than the interior. In this situation, brine is expelled from the sheet in both directions. As a result, the gross salinity (total salt content) of the sheet decreases with time, and the brine channels remain to form a continuous pathway from the base to the ice surface.

Oil released during the cold months will migrate only a few $\mathrm{cm}$ before becoming trapped in the ice sheet. This has been observed in ice cores extracted throughout the winter, with the vertical rise depending largely on the internal ice temperature. Oil will tend to rise in the ice to the level where the temperature is close to $8^{\circ} \mathrm{C}$. Depending on the ice thickness at the time of the spill, an initial vertical migration of $10-20 \mathrm{~cm}$ could occur rapidly, with the oil stabilizing at that level until the ice sheet warms further in the spring. Late in the season, when the ice warms and continuous brine channels form, trapped oil is released and migrates rapidly to the surface.

\section{Detecting oil under ice with GPR}

In GPR studies, a transmitting antenna generates an oscillating electric field that propagates through the subsurface and is reflected back toward a receiving antenna at boundaries separating materials with differing electric properties (dielectric permittivity and conductivity). Dielectric permittivity largely controls propagation velocity and reflectivity, while 
signal attenuation is primarily a function of conductivity with high conductivity leading to increased signal attenuation. The reflected wavefield is recorded and used to produce a reflector map that indicates subsurface electric property contrasts. The large permittivity contrast between sea ice and sea water $(-5: 88)$ and between sea ice and oil $(-5: 2.2)$ suggests that GPR should be sensitive to the presence of oil at the ice/ water interface, and a number of published studies use GPR to image the sea ice/sea water contact.

For operations at the upper end of the GPR frequency spectrum (500-1000 MHz), the dominant wavelength in sea ice ranges from 30 to $15 \mathrm{~cm}$, respectively. We expect that often spilled oil will form pools or films just a few centimeters thick, leading to the necessity of thin-bed analysis. In this case, rather than relying on a direct measure of traveltime differences, detailed measurements of the waveform are used to detect the presence of thin layers and characterize their properties. As with seismic reflection data, the standard instantaneous attributes (amplitude, frequency, and phase) can be powerful tools for detecting the presence of thin-layer anomalies. Amplitude, frequency, and phase measurements can be made from typical fixed-offset GPR data, which are relatively fast and inexpensive to acquire.

Sea water strongly attenuates the radar signal, with the rate of attenuation increasing as the dissolved solid concentration (electric conductivity) increases. Thus, brine contained within pockets or channels in ice may limit signal penetration. When sea ice forms, predominant ocean currents cause preferred alignment of the c-axis of the ice crystals. This in turn results in a preferred alignment in the distribution of brine within the ice matrix which produces directionally dependent electric conductivity. Most commercial GPR systems utilize linear dipole antennas. When the antenna is parallel to the $c$-axis of the ice, the electric field polarization is also parallel to the c-axis, and the signal undergoes maximum attenuation. Conversely, when the antenna is perpendicular to the c-axis, the signal undergoes minimum attenuation. It is important to recognize that entrapped brine and sea-ice anisotropy may alter the measured GPR attributes and that these characteristics may not easily be quantified in field data, but should be considered.

\section{Work flow for numerical modeling}

To produce quantitatively useful GPR models, it is necessary to first build realistic electric property models. Sea ice is a complex mixture of brine and ice crystals and the electrical properties depend on both temperature and salinity. We developed an electric property algorithm based on the relationships given by Morey et al. (1984) that utilize ice temperature and salinity as the only parameter input. The algorithm proceeds as follows:

1) Input the measured temperature ( $T$ ) and bulk salinity profile (S).

2) Compute brine volume $\left(V_{b}\right)$ as a function of $T$ and $S$.

3) Compute the brine salinity $\left(S_{b}\right)$ as a function of $T$.

4) Compute the brine conductivity $\left(\sigma_{b}\right)$ as a function of $S_{b}$ and $\mathrm{T}$.

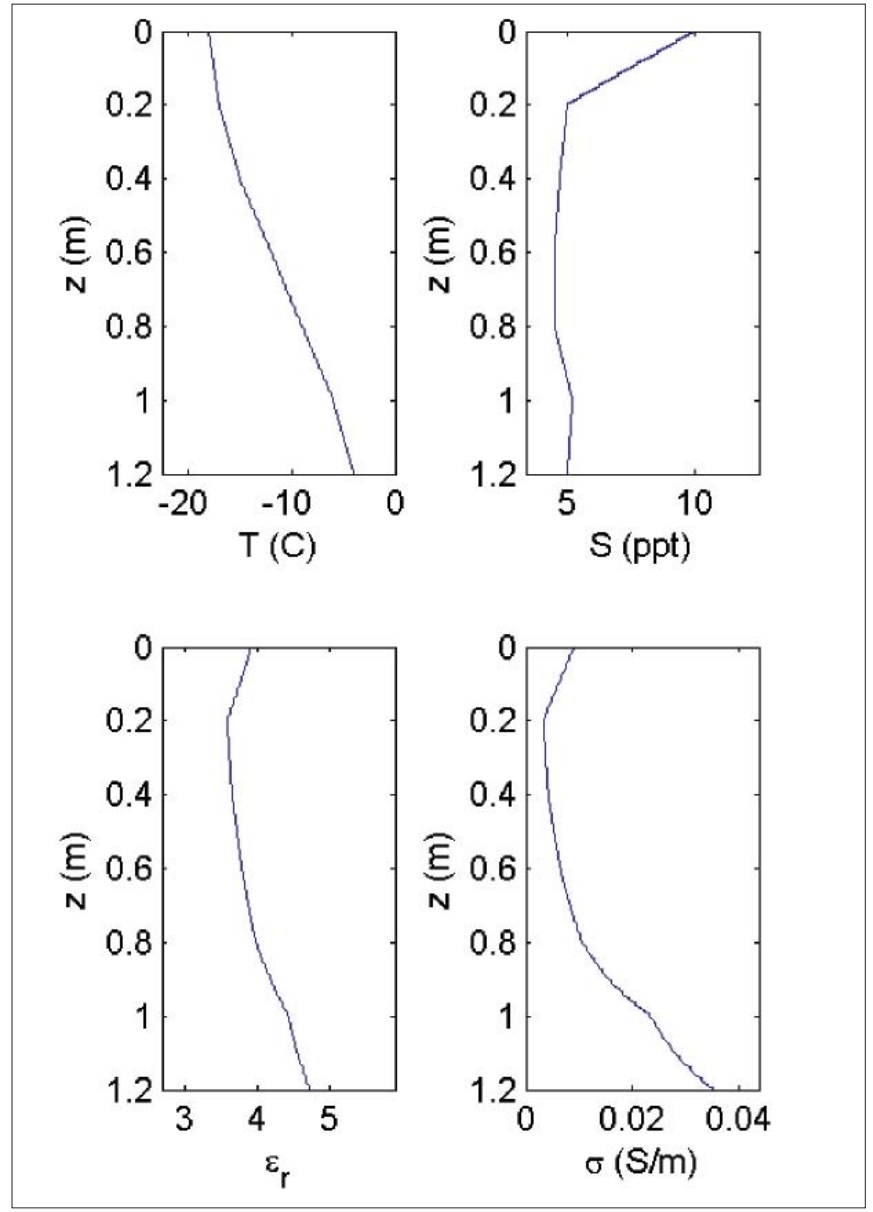

Figure 1. Ice property model with temperature (T) and salinity profiles (S) based on February field measurements in the Beaufort Sea. Electric properties relative dielectric permittivity $\left(\varepsilon_{r}\right)$ and electric conductivity $(\sigma)$ are computed from the temperature and salinity profiles using the algorithm described in the text.

5) Compute the complex dielectric permittivity of the brine $\varepsilon_{b}$ at the dominant radar frequency as a function of $T$ and $\sigma_{b}$.

6) Compute the bulk electric conductivity using Archie's law as a function of $\mathrm{V}_{\mathrm{b}}$ and $\sigma_{\mathrm{b}}$ and imaginary component of $\varepsilon_{\mathrm{b}}$; then output to wave propagator. Simulation of the electric field polarized either parallel or perpendicular to the ice crystal alignment is accomplished through choice of the Archie's law exponent ( 1.5 for parallel or 1.75 for perpendicular polarization).

7) Compute the bulk dielectric permittivity as a function of $\mathrm{V}_{\mathrm{b}}$, the real component of $\varepsilon_{\mathrm{b}}$ and the permittivity of crystalline ice using a multiphase mixing formula such as the CRIM equation; output to wave propagator.

Temperature and salinity profiles, and associated effective conductivity and permittivity profiles are shown in Figure 1.

\section{Model GPR response to oil at the ice/water interface}

First, consider variation in GPR attributes as a function of oil thickness. To model the GPR response in this case, we use a reflectivity model to compute the plane-wave solution at 

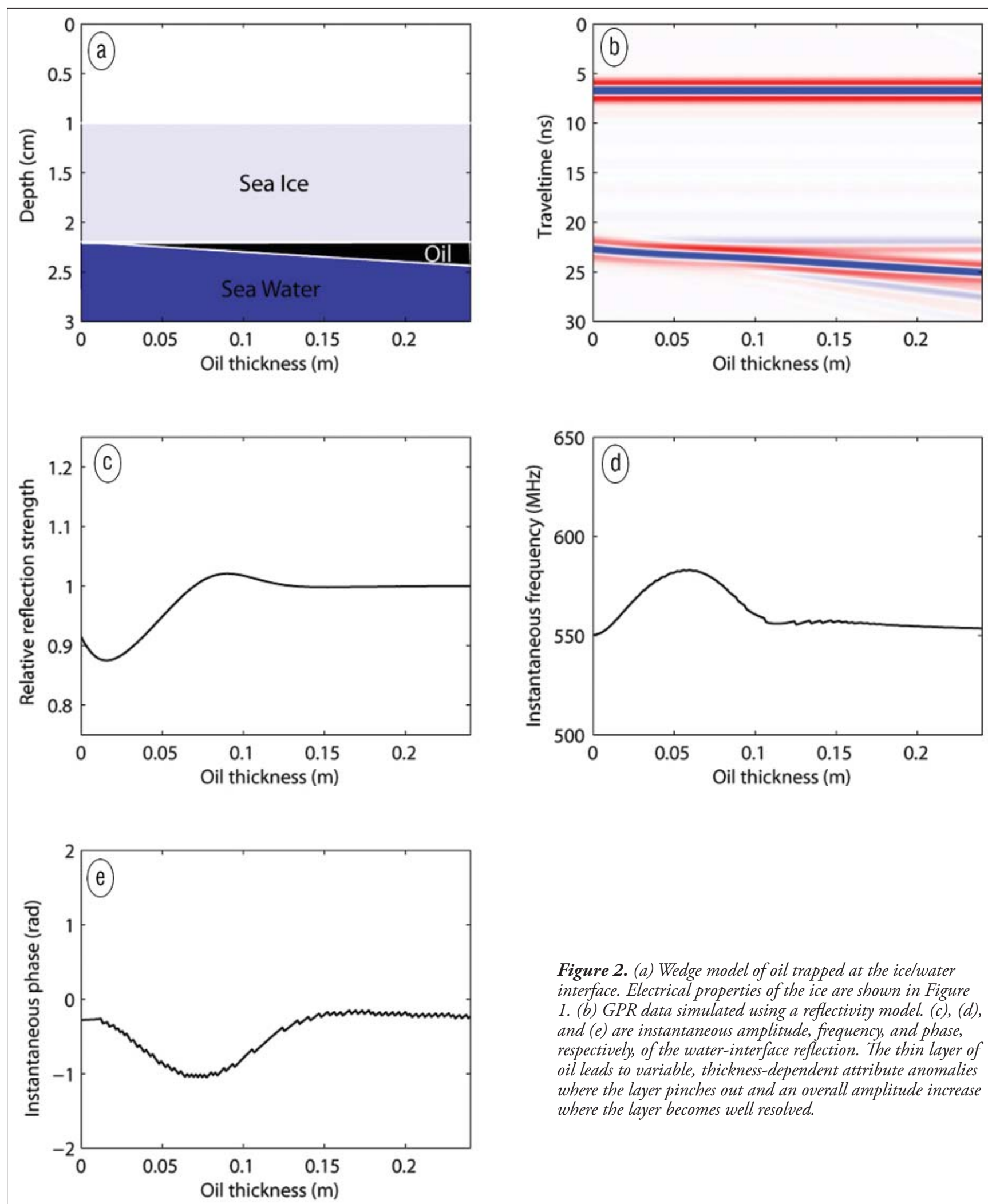

Figure 2. (a) Wedge model of oil trapped at the ice/water interface. Electrical properties of the ice are shown in Figure 1. (b) GPR data simulated using a reflectivity model. (c), (d), and (e) are instantaneous amplitude, frequency, and phase, respectively, of the water-interface reflection. The thin layer of oil leads to variable, thickness-dependent attribute anomalies where the layer pinches out and an overall amplitude increase where the layer becomes well resolved.

normal incidence. To account for the vertical electric property gradients, we divide the permittivity and conductivity profiles into homogenous layers with thickness of $5 \mathrm{~mm}$. The source is a $500-\mathrm{MHz}$ Ricker wavelet placed $1 \mathrm{~m}$ above the ice surface. Using the electric properties for February Beaufort
Sea conditions, we varied the oil thickness from 0 to $24 \mathrm{~cm}$ (Figure 2a). We set the oil relative permittivity to 2.2 (the dominant wavelength in the oil is $-40 \mathrm{~cm}$ ).

The simulated GPR data (Figure 2b) contain qualitative changes including an amplitude increase as the oil layer thick- 
ens. At a thickness of $24 \mathrm{~cm}$, the oil layer is well resolved, and the relatively weak reflection from the ice/oil interface is easily differentiated from the oil/ water reflection. At thicknesses of 0 to $14 \mathrm{~cm} \mathrm{(}-1 / 3$ wavelength), significant anomalies are observed in the instantaneous attributes for the water-interface reflection. The amplitude first decreases slightly, reaching a minimum at $4 \mathrm{~cm}$ of oil (Figure 2c). The amplitude then increases, reaching a maximum at 12 $\mathrm{cm}$ of oil, or slightly more than $1 / 4$ of a wavelength. As the oil layer becomes well resolved, the amplitude reaches a constant value controlled by the oil/ water plane-wave reflection coefficient. The instantaneous frequency increases by $35 \mathrm{MHz}$, reaching a maximum at 9 $\mathrm{cm}$ of oil and then decaying to the constant background level (Figure 2d). A phase delay is also associated with the thin oil layer, reaching -0.86 radians at $10 \mathrm{~cm}$ of oil (Figure 2e).

These results illustrate that GPR

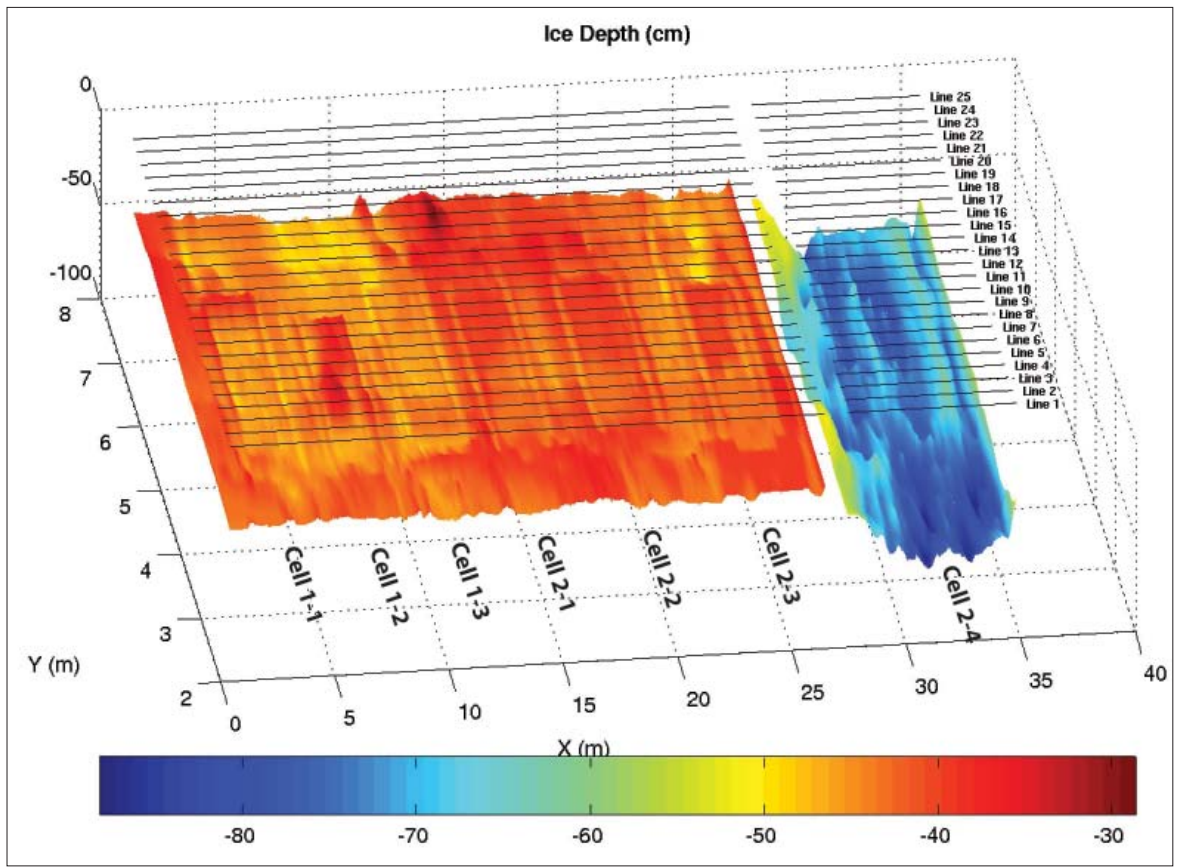

Figure 3. Depth to ice/water interface mapped using 3D GPR and surface location of GPR profiles. The data were acquired using an 800-MHz common-offset antenna configuration. Image is aligned in the long dimension of the tank with smooth ice on the left and rough ice (blue) on the right. Outlines of the six smooth-ice spill skirts are seen as ice thickness anomalies.

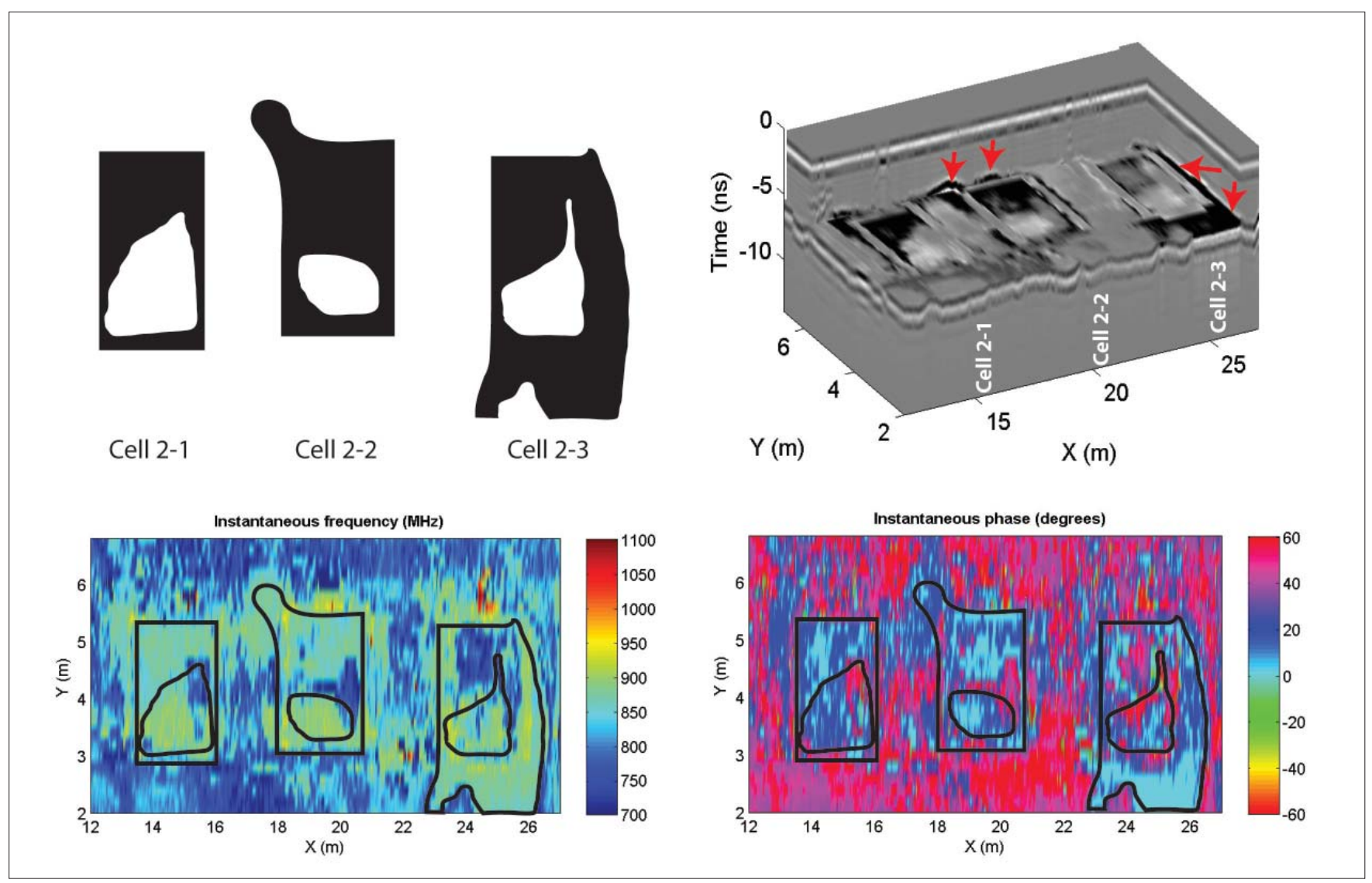

Figure 4. Oil distribution mapped from overhead photos with backlighting from beneath the ice. Slice through the data volume clearly shows amplitude highs (dark black) associated with oil that has accumulated in topographic highs. Red arrows indicate location of oil outside the containment skirts. Instantaneous attributes also show anomalies that track the oil distribution. Although there are some false positives, approximately $80 \%$ of the oiled area is identified from the GPR response. 

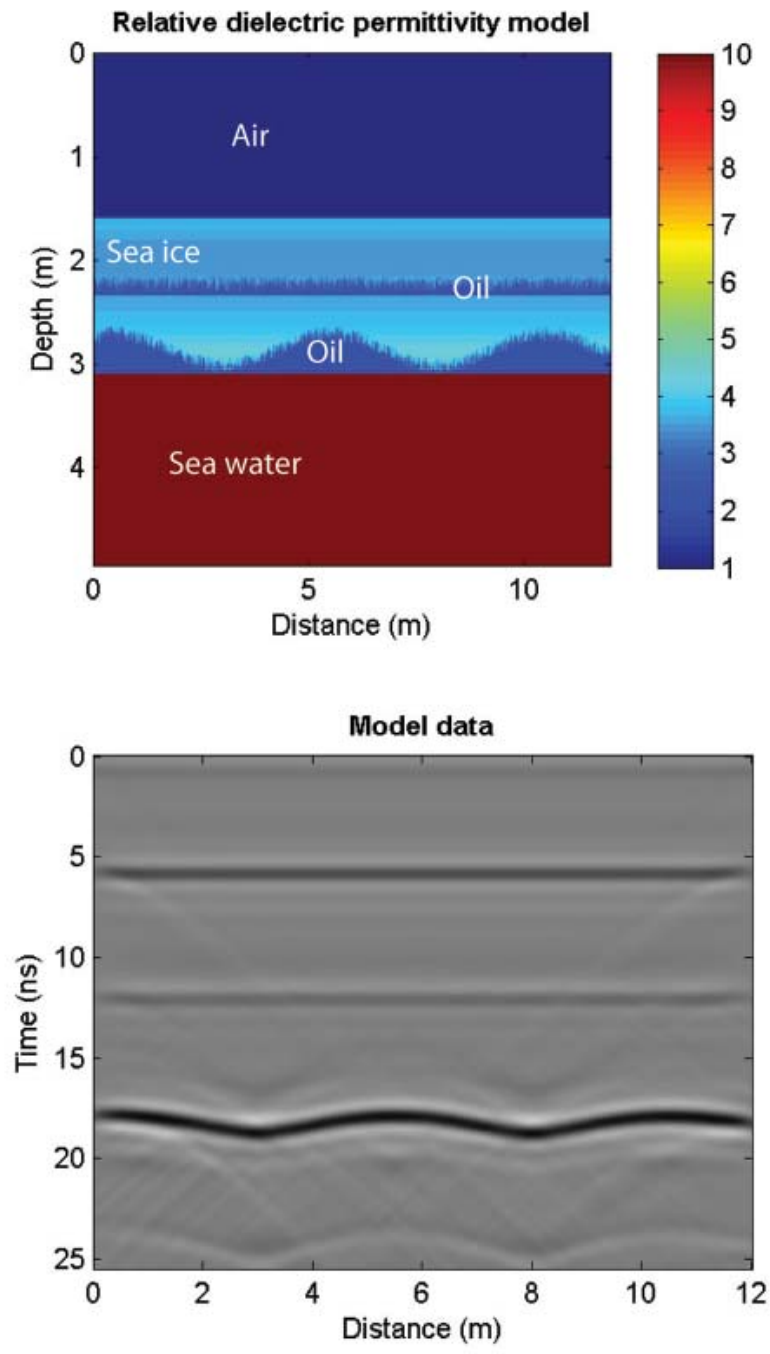
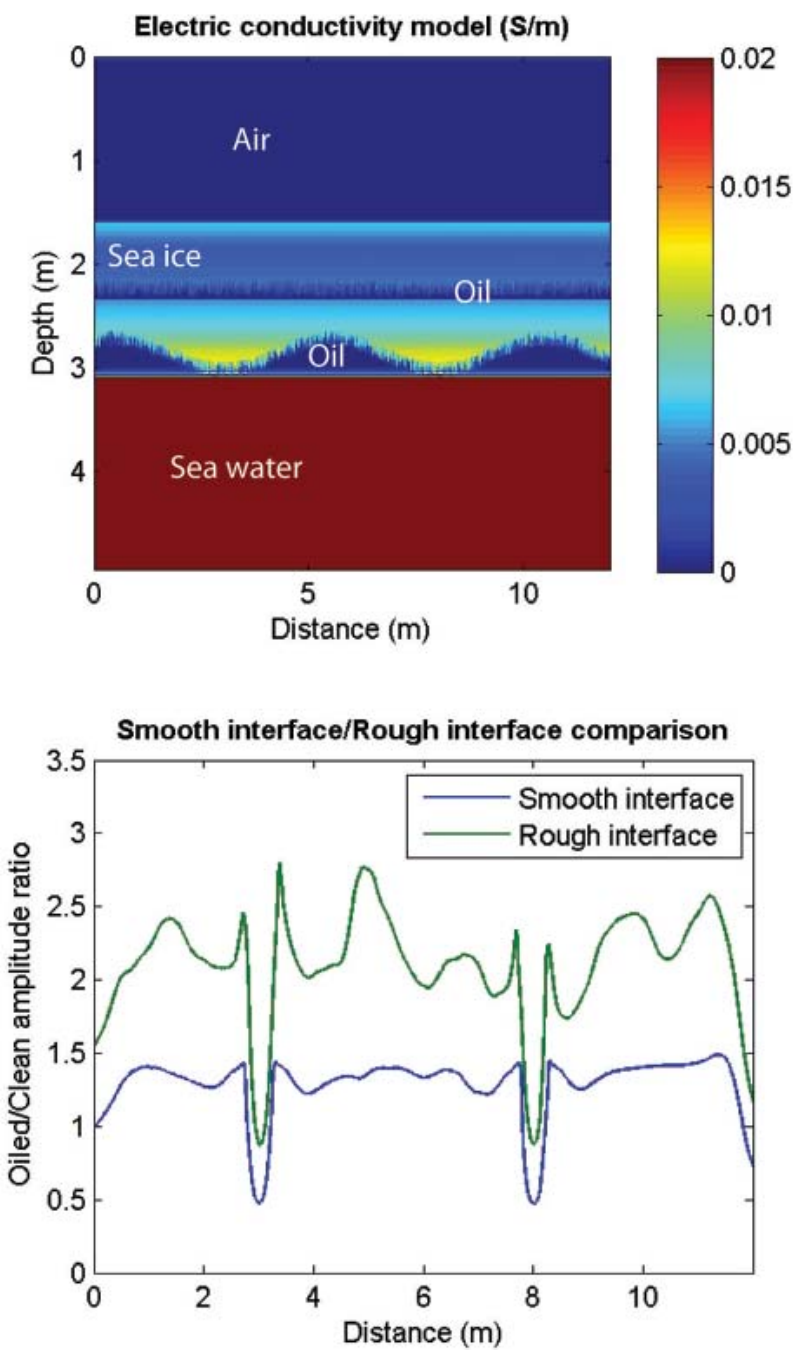

Figure 5. Electric property models and simulated GPR data for a laterally variable icelwater interface oil migration of up to $12 \mathrm{~cm}$ into the ice sheet simulated with a rough interface varied randomly at 3-mm intervals. The relative permittivity of cold sea water is $\sim 88$, but the plot is clipped at 10 so that variations in the ice sheet are evident. The properties are based on our February test case shown in Figure 1. An earlier spill resulting in oil trapped within the ice sheet is also present in this model. Although this layer generates a reflection, it does not alter the attributes at the base of the ice. The amplitude change caused by introduction of oil at the icelwater interface is roughly a factor of 2 higher in the case of rough ice relative to the smooth-ice equivalent.

should be sensitive to the presence of oil at the ice/water interface. The reflection from the water interface is the highest amplitude event in the reflected wavefield and therefore relatively easy to identify in field data. Substantial differences in various aspects of the reflection response along the water interface are present for oil layers thicker than $2-3 \mathrm{~cm}$. These changes offer the potential to differentiate the GPR response over oiled areas from the background or clean response.

\section{Laboratory test}

To test GPR performance in real ice, we conducted a controlled spill experiment at the Ice Engineering Facility at the U.S. Army Cold Regions Research and Engineering Laboratory (CRREL) in Hanover, New Hampshire which houses a large ice test basin, $36.5 \mathrm{~m}$ long $\times 9 \mathrm{~m}$ wide $\times 2.4 \mathrm{~m}$ deep. The test basin is contained within a cold chamber that maintains a controlled freezing environment down to $-30^{\circ} \mathrm{C}$. The tank is filled with $1 \%$ urea water which produces a final ice crystal structure very similar to sea ice, with impurities trapped in brine channels.

The ice sheet was grown by maintaining the test chamber at $-30^{\circ} \mathrm{C}$ for 16 days. The resulting ice (thickness of $30-40$ $\mathrm{cm}$ in the smooth ice section) showed significant spatial variations $( \pm 15 \%)$ in ice thickness. This outcome benefited the experiment in that the oil tended to spread under the ice in an irregular manner, closely mimicking actual arctic spill behavior.

Spills were contained within seven weighted skirts hanging $46 \mathrm{~cm}$ into the water from a buoyant square frame $(2.4 \mathrm{~m}$ on a side) of plastic pipe. The floating frames were positioned at intervals down the centerline of the tank at the onset of ice growth and allowed to freeze-in starting at cell 1-1 and end- 
ing with 2-4 in the rough ice field (Figure 3). The technique of inserting flexible fabric skirts through the ice to contain oil was used successfully in a number of previous experimental spills in natural sea ice. The hoops or skirts need only to hang a few feet under the completed ice sheet to fully contain any oil injected inside the skirt perimeter.

South Louisiana crude was selected for the experiment due to availability and a low pour point, which ensured that it would remain a liquid in the tank water at $-0.3^{\circ} \mathrm{C}$. The total available volume of 200 US gallons was portioned between the spills according to three nominal film thicknesses $(8,15$, and $30 \mathrm{~mm}$ ), assuming an even distribution within the skirted areas. The oil spreading was far from uniform. The target minimum film thickness of $8 \mathrm{~mm}$ corresponds to the minimum equilibrium film thickness under sea ice, which varies from 6 to $8 \mathrm{~mm}$ depending on the interfacial tension between oil and sea water. Fresh crude oil was pumped beneath the ice at two stages in the growth cycle: into three hoops or spill skirts once the ice thickness was between 17 and $25 \mathrm{~cm}$, and into the remaining four spill rings once the ice was close to its maximum thickness (morning of the first test day). This spill sequence resulted in a mix of free oil under the ice in sites 2-1 to 2-4 (ice/water/oil interfaces) and entrapped oil in sites 1-1 to 1-3 (ice/oil/ice interfaces). Here we focus on the three cells with oil trapped beneath the ice (cells 2-1 to 2-3).

The contaminated areas were digitized from overhead photographs taken with underwater backlighting. Backlighting clearly revealed the location of oil trapped under the ice (Figure 4). Note that a significant amount of oil escaped containment skirts 2-2 and 2-3. The breach of the test cells was not known prior to GPR data acquisition and inadvertently created a blind test for the GPR experiment.

We acquired 3D data over all test cells using a Mala GPR system with $800-\mathrm{MHz}$ antennas. The $3 \mathrm{D}$ patch was $4.8 \times$ $27 \mathrm{~m}$. The data consisted of 25 parallel profiles on $20-\mathrm{cm}$ centers (Figure 3). We acquired traces at intervals of $-2 \mathrm{~cm}$ using a studded odometer wheel trigger and then applied a geometry correction for small amounts of odometer wheel slip using the known cell boundaries which produced discontinuities clearly evident in the GPR data. Eight radar pulses were stacked at each location to enhance signal.

The data processing flow consisted of: time-zero shift to correct for instrument drift; band-pass filtering to remove the low-frequency transient (wow) and high-frequency random noise; spherical spreading correction; and attribute computation via the Hilbert transform.

The ice/water interface produced a clear, well-defined reflection that enabled detailed mapping of the ice thickness. Amplitude anomalies were present throughout the survey area, with the largest and most extensive observed in cells 2-1, $2-2$, and on the southeast side of cell 2-2 and north and west of cell 2-3 where oil breached the containment skirts. Slicing the GPR data volume through the shallower portion of the ice/water reflection reveals well defined amplitude anomalies that track the oil distribution in and around cells 2-1, 2-2, and 2-3 (Figure 4). Of particular interest are the oil-induced anomalies outside of cells 2-2 and 2-3. Note that we identified these anomalies and predicted that oil was present outside the test cells prior to backlighting the ice and mapping the oil distribution. Slicing through the data at the upper part of the water reflection combines two effects: (1) the oil migrates to the topographic high points, and (2) the oil produces a highamplitude anomaly. Amplitude highs unrelated to the oil are also evident around the skirt boundaries and at a few other locations where topographic variations cause focusing of the radar energy.

After plotting the instantaneous phase and frequency along the water interface horizon, we find an increase in frequency and a phase lag associated with the presence of oil. These anomalies are expected from the numerical model results. Note that these attributes are relatively noisy and that some anomalies are present where there is no oil. Additionally, there are some oiled areas where no anomaly is observed. Recall, however, that the attribute response depends strongly on the oil thickness and is nonunique.

The amplitude anomalies associated with the oil are roughly five times larger than predicted by the simple reflectivity model, and there are significant attribute anomalies within the test cell where no oil was revealed by underwater backlighting. These observations can be explained by recognizing that the ice undersurface is not smooth, but is roughened by irregular crystal growth extending below the solid ice sheet. The trapped oil tends to fill in these irregularities, resulting in a smaller property contrast between ice and oil at the rough interface and creating a smooth boundary at the oil/water interface. These effects combine to enhance the amplitude response. Additionally, underwater photography after the experiment revealed that disconnected droplets of oil were present beneath the ice throughout the test cells but away from the oil pools. These droplets filled in ice irregularities and created a more uniform reflecting horizon leading to attribute anomalies.

To test the effect of fine-scale roughness at the base of the ice, we inserted sinusoidal variations at the base of the ice model with a 5-m wavelength and peak-trough height of $20 \mathrm{~cm}$ (Figure 5). Ice properties were those shown in Figure 1. We used a second-order finite-difference GPR simulator with a plane-wave source $1.5 \mathrm{~m}$ above the ice surface. We simulated a spill scenario by filling the peaks with oil and modeled both smooth and rough ice/water interfaces. The rough surface was constructed by randomly perturbing the ice thickness by $0-12 \mathrm{~cm}$. These variations occur over $2-3$ $\mathrm{mm}$ laterally, which is comparable to the width of brine channels within natural sea ice.

Comparing the amplitude ratios of oiled-to-clean scenarios, we see that the amplitude increase is a factor of up to two times greater in the case of rough ice (Figure 5). Therefore, oil present at the irregular interface in natural sea ice tends to enhance attribute anomalies.

\section{Natural sea-ice test}

In collaboration with SINTEF, we conducted a controlled 


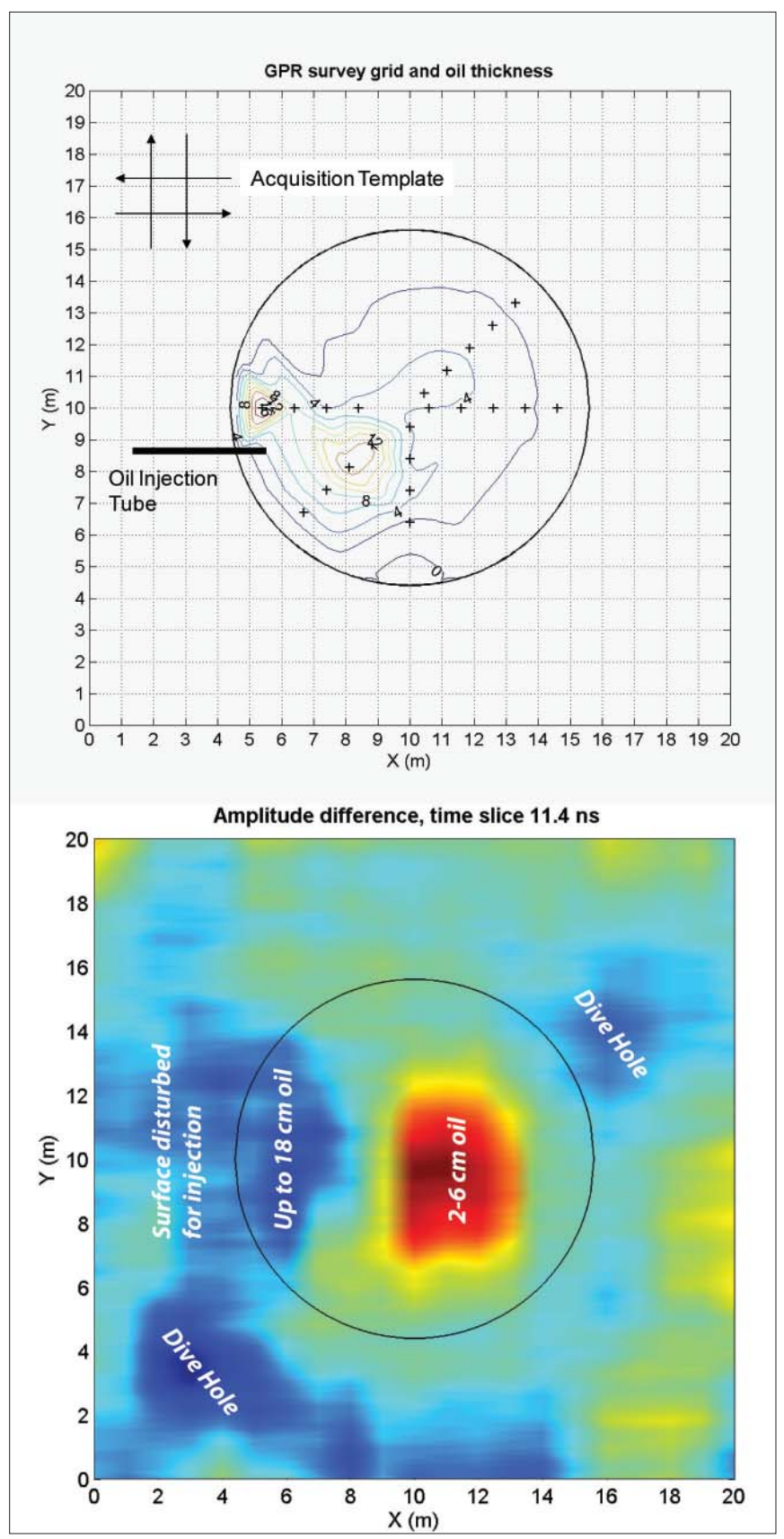

Figure 6. Layout of the $3 D$ GPR grid including the mapped oil distribution and instantaneous amplitude anomaly at the ice/water interface. Data were acquired on 1-m centers on an orthogonal grid. + signs = control points for oil thickness measurements. The contour interval is $2 \mathrm{~cm}$. A clear amplitude increase is evident where the oil thickness is 2-6 cm. On the left of the cell, where the oil thickness is greatest near the injection point, amplitudes are generally lower after oil injection indicating a lower contrast between the ice and oil than between the ice and water. Amplitude anomalies outside the test cell are caused by surface disturbance during injection preparation.

spill experiment near Sveagruva, Svalbard, Norway in March 2006 to test the radar performance under natural sea-ice conditions. Note that 2006 was a particularly warm year, as such we had a relatively thin, warm ice $\left(-65 \mathrm{~cm}\right.$ and $\left.>-7^{\circ} \mathrm{C}\right)$ sheet to work with. This scenario represented likely limiting conditions under which GPR could be effectively deployed. The oil was contained by a plastic skirt (diameter of 11.2 $\mathrm{m}$ ) inserted through $45 \mathrm{~cm}$ of ice in February and allowed to freeze in until the time of the experiment in late March. The skirt depth of $150 \mathrm{~cm}$ allowed ample material to hang beneath the ice.

Oil was injected under the ice and inside the skirt through a neutrally buoyant pipe inserted through an augur hole drilled at an angle just outside the skirt. A total of 3400 liters (18 drums) of Statford crude were pumped from drums over a period of 2 hours and 10 minutes. The progress of the oil injection was monitored and recorded by an underwater camera focused on the end of the injection pipe approximately 1 $\mathrm{m}$ inside the skirt. The same camera was periodically moved to different inspection holes around the skirt perimeter to monitor the progress of the advancing oil boundary. No oil was observed outside the skirt during and after the oil injection by the underwater camera, and no sheen was observed in the inspection holes outside the skirt. Topographic variability at the base of the ice resulted in an irregular oil distribution with oil thickness ranging from 0 to $18 \mathrm{~cm}$ (Figure 6).

We acquired GPR data with a Sensors and Software PulseEKKO Pro sytem using $500-\mathrm{MHz}$ antennas. Surveys were conducted before and after oil emplacement along 42 profiles in a $20 \times 20$-m orthogonal grid with 21 profiles in each direction. The orthogonal grid was important to test for azimuthal anisotropy in the GPR response related to the preferred orientation of ice crystal formation. Trace spacing of $5 \mathrm{~cm}$ was controlled by a studded odometer wheel. No significant wheel slippage occurred. Repeatability outside the containment cell was compromised by cutting dive holes after the background data set was acquired. While this effect is certainly evident in the data, it did not affect the response within the target area.

Data processing included: a time zero correction; a bandpass filter; relative amplitude gaining (data scaled to $t^{2}$ ) followed by trace normalization; and instantaneous attribute computation.

Figure 7 shows cross-sections of the data before and after oil emplacement. Before oil emplacement, a topographic high (or area of relatively thin ice) is evident at low values of $y$ between $\mathrm{x}=5$ and $9 \mathrm{~m}$. This created a preferred oil accumulation zone and the thickest oil films were measured in this area (Figure 6). After oil emplacement, the reflection from the base of the ice within the containment skirt undergoes a phase rotation of $180^{\circ}$ in areas of thickest oil. This obvious change in the reflectivity occurs because crude oil has a much lower dielectric permittivity (higher velocity) than sea ice resulting in a positive-to-negative reflection coefficient change at the base of the ice. The reflection from the base of the oil pool is also evident as a flat-lying reflection with the same polarity as the ice/water interface reflection outside the containment area. However, the amplitude is much lower than expected. We believe this to be related to emulsification of the oil during injection leading to a higher conductivity mixture that inhibits GPR signal penetration.

Toward larger $\mathrm{x}$ and $\mathrm{y}$ values (Figure 6), the oil film thins 
and is no longer clearly resolved, but we record a significant amplitude increase after oil emplacement. The ice/water interface in this area appears irregular and generates a very weak reflection prior to oil emplacement. A possible interpretation is that water currents within the test cell are altered because of the containment skirt protruding into the water column. Decreased current flow may allow for more irregular crystal growth. Again, oil trapped within this rough interface tends to smooth irregularities and enhance the pre- and post-oil emplacement amplitude difference. The GPR amplitude response to the oil emplacement is highlighted by slicing the amplitude difference volume horizontally at the ice/water interface. Consistent amplitude highs are observed where the oil has a thickness of 2-6 cm. The highamplitude anomaly has two sources: tuning where the layer thickness is less than $1 / 2$ wavelength, and oil filling in irregularities in the base of the ice.

GPR, operating at $500 \mathrm{MHz}$, clearly delineated changes at the ice/ water interface caused by emplacement of oil. Based on a qualitative comparison of the measured oil thickness distribution and radar results, it appears that the lower detection limit at $500 \mathrm{MHz}$ is on the order of $2-4 \mathrm{~cm}$; however, the sparse distribution of oilthickness measurements prevents a detailed analysis.

\section{Discussion and conclusions}

For all field, lab, and modeling scenarios tested, results indicate that GPR methods can detect oil films as long as adequate energy reaches the ice/water interface. The minimum oil film detection limit appears to be roughly $2 \mathrm{~cm}$ with 500 $\mathrm{MHz}$ antennas. The response is nonunique, however, and successful detection requires an understanding of the system coupled with careful interpretation.

In addition to lateral heterogeneity at the surface and within the ice matrix, complexity at the ice/water interface has a significant impact on the GPR attributes. Measurement of these variations is not practical but would be required to compute oil-film thicknesses from the GPR response. Therefore, while it is possible to determine whether oil is present or not, it is unlikely that meaningful measurements of oil thickness can be made under typical field conditions.
Brine volume is the primary factor limiting signal penetration. There is a critical point at around $-5^{\circ} \mathrm{C}$ above which the brine volume results in high electric conductivity, and radar signal penetration is severely limited. In cold, midwinter ice, GPR can consistently penetrate the full ice thickness, but late in the season, thick warm ice prevents effective signal penetration. In the early season, the young ice tends to be relatively warm and have high salinity; however, since the ice is thin, it may still be possible to penetrate to the ice/water interface. Our field tests have shown that GPR operating below $800 \mathrm{MHz}$ is necessary to consistently reach the ice/water interface, and we consider $-500 \mathrm{MHz}$ the optimal operating frequency for the oil-detection problem. Within the limitations noted here, GPR can now be considered as an operational tool to detect oil in a wide range of ice conditions.

The modeling tools developed as part of this project produce realistic simulations of field conditions. This is in part 
because actual measured values, specifically ice temperature and salinity, are used as primary inputs to the model. Based on the analytical tools we have developed, models can now be constructed and run in a matter of a few hours for any specific scenario. A recommended strategy for deployment of GPR during an actual spill then becomes:

1) Collect a sample of the spilled oil if available, and measure its dielectric permittivity. This can be done rapidly using a time-domain reflectometry probe or the GPR system itself.

2) Acquire ice thickness, temperature, and salinity profiles from the spill area.

3) Run numerical model with varying oil thickness to verify applicability of GPR to particular spill conditions and predict expected response.

Following this protocol will enable responders to deploy the system appropriately and maximize the likelihood of successful oil detection.

Suggested reading. "Instantaneous spectral analysis: Time-frequency mapping via wavelet matching with application to 3D GPR contaminated site characterization" by Bradford and Wu (TLE, 2007). Advancing Oil Spill Response in Ice Covered Waters by Dickins (published in conjunction with the US Arctic Research Commission, 2004). Svalbard Experimental Spill to Study Spill Detection and Oil Behavior in Ice by Dickins et al. (U.S. Minerals Management Service, 2006). "Equations for determining the brine volume of sea ice from $-0.5 \mathrm{C}$ to -22.9 C" by Frankenstein and Garner (Journal of Glaciology, 1967). "Electromagnetic properties of sea ice" by Morey (Cold Regions Science and Technology, 1984). "Profiles of floating ice in Arctic regions using GPR" by Nyland (TLE, 2004). Ice Mechanics: Risks to Offshore Structures by Sanderson (Graham and Totman, 1988). TEE

Acknowledgments: The U.S. Department of Interior, Minerals Management Services provided partial funding for this work under contract numbers 1435 01-04-36285, 1435-0106-CT-3925, and MO7PX13062. Funding was also provided by Alaska Clean Seas Inc., Alaska Department of Environment Conservation, Statoil ASA, ConocoPhillips, BP Exploration, Shell Technology Norway, ExxonMobil, and Store Norske Spitsbergen Kullkompani. Len Zabilansky and his staff conducted the oil release and clean up at CRREL. Per Johan Brandvik and the SINTEF staff conducted the oil release, monitoring, and clean up for the Svalbard experiment. Leah Steinbronn contributed to developing the modeling codes.

Correspondingauthor: johnb@cgiss.boisestate.edu 